\title{
H-mode access and the role of spectral shift with electrode biasing in the TCABR tokamak
}

G. G. Grenfell, I. C. Nascimento, D. S. Oliveira, Z. O. Guimarães-Filho, J. I. Elizondo, A. P. Reis, R. M. O. Galvão, W. A. H. Baquero, A. M. Oliveira, G. Ronchi, W. P. de Sá, J. H. F. Severo, and T CABR Team

Citation: Physics of Plasmas 25, 072301 (2018); doi: 10.1063/1.5029561

View online: https://doi.org/10.1063/1.5029561

View Table of Contents: http://aip.scitation.org/toc/php/25/7

Published by the American Institute of Physics

\section{Articles you may be interested in}

Effect of $\nabla B$ drift on the $\mathrm{H}$-mode power threshold in upper single null plasmas with ITER-like tungsten divertor on EAST

Physics of Plasmas 25, 072504 (2018); 10.1063/1.5033983

Characteristics of the SOL turbulence structure in the first experimental campaign on W7-X with limiter configuration

Physics of Plasmas 25, 072502 (2018); 10.1063/1.5033353

Effects of RF plasma modification on the thermal and mechanical properties of electrospun chitosan/poly(vinyl alcohol) nanofiber mats

Journal of Vacuum Science \& Technology B 36, $04 \mid 101$ (2018); 10.1116/1.5030507

Burst temperature from conditional analysis in Texas Helimak and TCABR tokamak

Physics of Plasmas 25, 042301 (2018); 10.1063/1.5025062

Large amplitude oscillatory shear: Simple to describe, hard to interpret

Physics Today 71, 34 (2018); 10.1063/PT.3.3971

Filamentary velocity scaling validation in the TCV tokamak

Physics of Plasmas 25, 072506 (2018); 10.1063/1.5038019

\section{PHYSICS TODAY}

MANAGER'S GUIDE

Accelerate R\&D with Multiphysics Simulation

\section{READ NOW}

PRESENTED BY

๑๐ $\subset$ MSOL 


\title{
$\mathrm{H}$-mode access and the role of spectral shift with electrode biasing in the TCABR tokamak
}

\author{
G. G. Grenfell, ${ }^{1, a), b)}$ I. C. Nascimento, ${ }^{1, b)}$ D. S. Oliveira, ${ }^{1}$ Z. O. Guimarães-Filho, ${ }^{1}$ \\ J. I. Elizondo, ${ }^{1}$ A. P. Reis, ${ }^{1}$ R. M. O. Galvão, ${ }^{1,2}$ W. A. H. Baquero, ${ }^{1, c)}$ A. M. Oliveira, ${ }^{1}$ \\ G. Ronchi, ${ }^{1}$ W. P. de Sá, ${ }^{1}$ J. H. F. Severo, ${ }^{1}$ and TCABR Team \\ ${ }^{1}$ Institute of Physics, University of São Paulo, 05508-090 São Paulo, Brazil \\ ${ }^{2}$ National Institute for Space Research, 12227-010 São José dos Campos, Brazil
}

(Received 15 March 2018; accepted 15 June 2018; published online 6 July 2018)

\begin{abstract}
The transition from the ohmic heating L-mode to the H-mode in the tokamak TCABR induced by an external electrode biasing is addressed in this work. A gradual improvement in the plasma confinement with the biasing voltage was observed as a result of the enhancement of the $E \times B$ shear flow at the edge. This result was supported by the measurement of plasma parameters in different radial locations by two electrostatic probes. Radial profiles of the electron temperature (from the standard sweeping voltage technique), electron density, and radial electric field, as well as the local turbulence features, were measured. We observed that the electron density profile became steeper as the voltage on the electrode increased, while no significant change in the temperature profile was noticed. In addition, the data were compared with the spectral shift model [G. M. Staebler et al., Phys. Rev. Lett. 110, 055003 (2013)] at different bias voltages, i.e., different $E \times B$ shear flows, showing a good agreement. Particularly, the gradual improvement was held: the higher the biasing voltage, the larger the radial wavenumber shift and so the turbulence suppression. Moreover, by studying the edge radial profile of the mean radial wavenumber, we show that the large shift occurs in the same position where the transport barrier is created. Published by AIP Publishing.
\end{abstract}

https://doi.org/10.1063/1.5029561

\section{INTRODUCTION}

Turbulence is the main mechanism responsible for the loss of particles and energy in relevant fusion devices. The control and/or suppression of this transport phenomenon has been one of the greatest challenges for the feasibility of future fusion reactors. Great progress in that direction was achieved in 1982 with the discovery of the high mode of confinement, H-mode, in the tokamak ASDEX: ${ }^{1}$ a plasma state where the energy and particle confinement time are increased up to a factor of two with respect to the low ohmic heating confinement, L-mode, as a result of turbulence suppression. Although more than three decades have passed since its discovery and the great effort made in understanding the phenomenon, both the trigger that yields the transition and the mechanism of turbulence suppression are still unclear. Such knowledge might be fundamental to set a closed H-mode model able to predict the plasma behavior in future fusion devices.

A widely accepted mechanism for turbulence suppression is the decorrelation of turbulent cells (eddies) driven by $E \times B$ shear flow. ${ }^{2,3}$ In fact, the decrease in the fluctuation levels can lead to the rise of an edge transport barrier (ETB), with a steeper pressure gradient and even higher shear flow. ${ }^{4}$ However, it was found that the suppression predicted by the

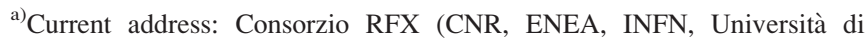
Padova, Acciaierie Venete SpA), C.so Stati Uniti 4, 35127 Padova, Italy.

b) Authors to whom correspondence should be addressed: inascime@if.usp.br and gustavo.grenfell@igi.cnr.it

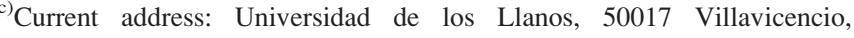
Colombia.
}

model was unable to explain the turbulence reduction from non-linear gyro-fluid simulations. 5,6

A different approach was proposed by the "quench rule." According to this model, the turbulence intensity reduces by $\operatorname{Max}\left[1-\alpha_{E}\left|\gamma_{E \times B} / \gamma_{\max }\right|\right]$, once the $E \times B$ velocity shear rate $\left(\gamma_{E \times B}\right)$ exceeds a threshold, where $\alpha_{E}$ is a positive constant and $\gamma_{\max }$ is the maximum linear growth rate at zero shear. ${ }^{5}$ This formula was successful in interpreting the GYRO simulations over a wide range of plasma parameters, but it was unable to compute the toroidal Reynolds stress. ${ }^{7-9}$

Despite the incompleteness of the analytical decorrelation models, several works have shown that $E \times B$ shear is a preponderant factor for the L-H transition. ${ }^{4,10}$ The importance of the radial electric field $\left(E_{r}\right)$ gradient as a key parameter in the L-H transition has been accepted theoretically, ${ }^{3}$ with the Doppler shear introduced as a turbulence-stabilizing mechanism, and experimentally with the detection of a constant $E_{r}$ well independent of the pedestal density. ${ }^{11}$ In the spontaneous H-mode achieved by plasma heating (e.g., ohmic, NBI, and ECRH), ${ }^{4}$ the $E_{r}$ profile changes mainly through the force balance equation, and it is influenced by the evolution of $\nabla p$ and the mean flow that, eventually, can be fed by the zonal flows. ${ }^{12}$ Even under specific heating conditions where only zonal flows apparently trigger the L-H transition just after an oscillatory phase understood as the inverse cascade phenomenon (predator-prey model ${ }^{13}$ ) the turbulence suppression does not occur without high enough shear levels. ${ }^{14}$ This exemplifies the universal role of the shear in the suppression of turbulence regardless of the actual trigger mechanism of the $\mathrm{L}-\mathrm{H}$ transition. 

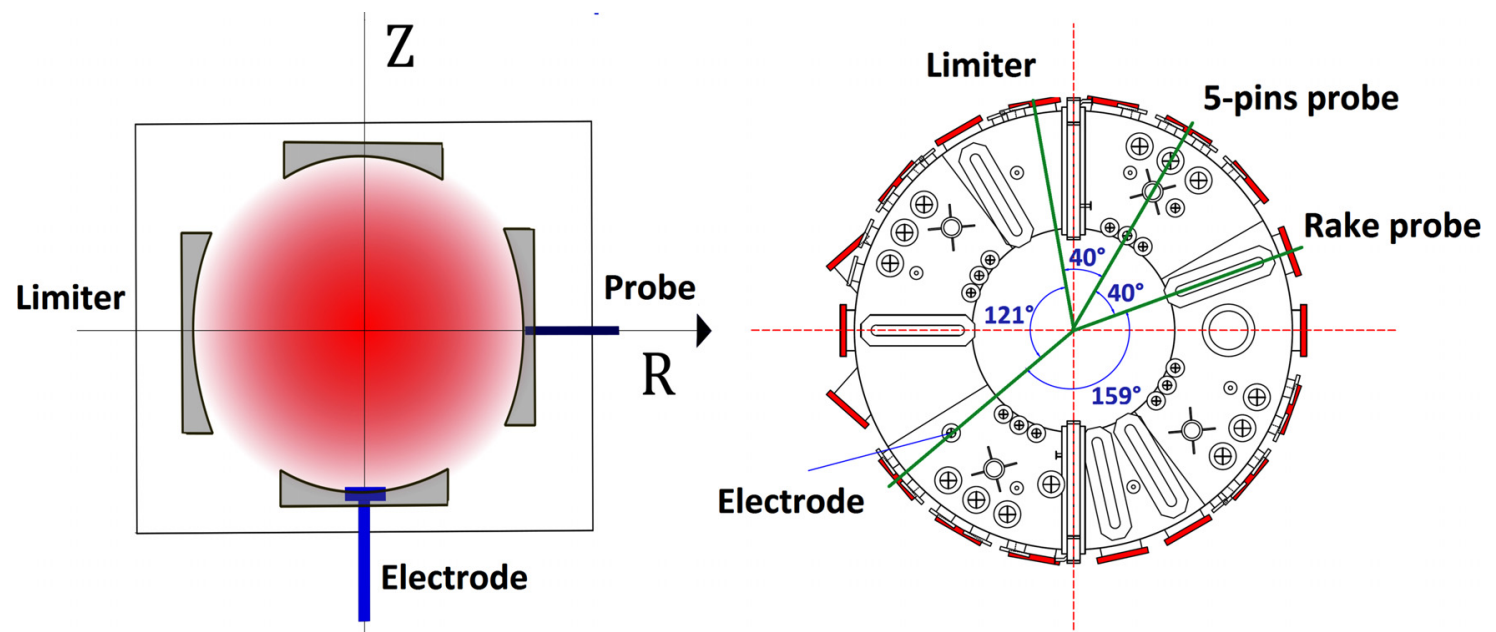

FIG. 1. On the left, a poloidal section highlighting the probe place at the midplane low field side, biasing the electrode inserted vertically from the bottom of the vessel and poloidally symmetric limiters. On the right, the top view of TCABR, showing the toroidal displacement between the two probes, limiter, and electrode.

Electrode biasing, used first by Taylor ${ }^{15}$ in 1989 and recently highlighted by Ochs and Fisch, ${ }^{16}$ is a technique that can be successfully used to modify the plasma edge. It is quite interesting for investigations of turbulence suppression mechanisms since the applied voltage access directly $E_{r}$, independent of the evolution of the force balance equation. In fact, the L-H transition and the role of the shear in biasing experiments have already been confirmed. ${ }^{17-25}$ Furthermore, since electrode biasing experiments are difficult to be performed in larger machines due to obvious limitations related to the insertion of probes and electrodes inside the plasma, such experiments are carried out on small machines with relative simplicity, which stage them in the forefront of current investigation of turbulence suppression mechanisms.

In this paper, we present experimental results from the electrode biasing campaign in the TCABR tokamak and discuss them in the framework of the spectral shift model. ${ }^{6}$ According to this new model, the turbulence suppression is understood as a consequence of a finite shift on the radial wavenumber spectrum due to the mean $E \times B$ velocity Doppler shift. ${ }^{6,9,26}$ The radial spectral shift also breaks the poloidal parity, resulting in a non-zero toroidal Reynolds stress and, therefore, avoiding the causality problem faced by the quench rule and the decorrelation model. Another feature of the model is that there is no need of an intermediate phase for explaining the reduction of the turbulence levels observed in the L-H transition although it admits limit cycle oscillation (LCO) under certain conditions. ${ }^{27}$ In this scenario, the transition and the turbulence suppression mechanism are controlled by a single parameter in the electrode biasing experiment, the edge gradient of $E_{r}$, i.e., the $E \times B$ shear flow.

This paper is organized as follows: In Sec. II, the experimental setup is shown. In Sec. III, the experimental results for the biasing voltage experiment in the TCABR tokamak, as well as the characterization of the plasma confinement improvement and the H-mode regime, are presented. In Sec. IV, we discuss the results in the framework of the spectral shift models and its main features. A brief overview of the results and the final remarks and conclusions are presented in Sec. V.

\section{EXPERIMENTAL SETUP}

The experiments were carried out in the tokamak $\mathrm{TCABR}^{28}$ in a hydrogen plasma of circular shape, limited by 4 graphite limiters displaced poloidally $90^{\circ}$ from each other in a poloidal section (Fig. 1). TCABR has minor radius $a=0.18 \mathrm{~m}$, major radius $R=0.615 \mathrm{~m}$, and toroidal magnetic field $B=1.07 \mathrm{~T}$. The maximum plasma current and the lineaveraged density are $I_{p}=100 \mathrm{kA}$ and $n=4.0 \times 10^{19} \mathrm{~m}^{-3}$, respectively, and the maximum temperatures for electrons and ions are $500 \mathrm{eV}$ and $230 \mathrm{eV}$, respectively. A biasing electrode of hard graphite, disc-shaped, with $20 \mathrm{~mm}$ diameter and $9 \mathrm{~mm}$ thickness, was inserted in the vertical plane from the bottom of the vessel. A movable system enables a variation up to $2 \mathrm{~cm}$ inside the plasma and $3 \mathrm{~cm}$ outside. The electrode power supply is composed of a large capacitor bank plus a triggered programmable fast-switch that sets the duration of the applied polarization. It allows a voltage up to $\pm 750 \mathrm{~V}$ and a maximum current of $300 \mathrm{~A}$ in a programmable square pulse of up to $20 \mathrm{~ms}$ duration. The rise time of the voltage was set as $10 \mu \mathrm{s}$. The $H_{\alpha}$ diagnostic is composed of a photodiode and a $10 \AA$ band-pass interference filter used to transmit the hydrogen $H_{\alpha}$ spectral line. It is installed in a window at the bottom of the vacuum vessel, $140^{\circ}$ counterclockwise from the limiter, and the line of sight is through the centre of the plasma column. The poloidal beta diagnostic system of the TCABR tokamak is installed in a vertical plane located at $140^{\circ}$ clock-wise from the limiter, and it is composed of a diamagnetic coil and compensation coils. Further details can be obtained in Ref. 29.

Two electrostatic probes were used in this experiment: a 5-pin probe [Fig. 2(a)] and a rake probe [Fig. 2(b)]. The probes data were acquired at a sampling rate of $2 \mathrm{MHz}$. The 5 -pin probe has all its pins in the same radial position but $5 \mathrm{~mm}$ poloidally displaced. The rake probe has its 18 pins divided into two rows, $2.5 \mathrm{~mm}$ toroidally shifted and $5 \mathrm{~mm}$ radial displacement. Both probes are installed in the midplane of TCABR, in a mechanical movable system. In this experiment, the biasing electrode was placed at $r=17.0 \mathrm{~cm}\left(r-r_{0}=-1 \mathrm{~cm}\right.$, 

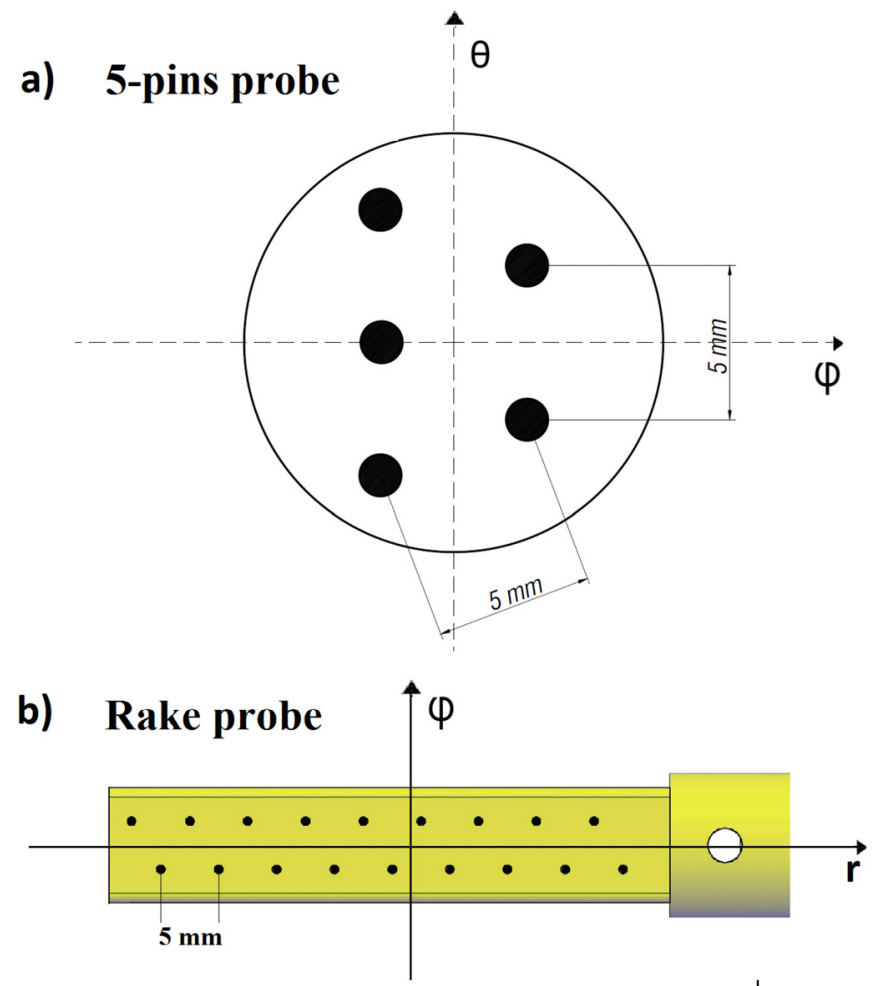

FIG. 2. Schematic diagram of the 5-pin probe (a) and the rake probe (b).

where $r_{0}$ is the limiter position), the rake probe at $r=17.0 \mathrm{~cm}\left(r-r_{0}=-1 \mathrm{~cm}-\right.$ position of the innermost pin), and the 5-pins probe at $r=17.5 \mathrm{~cm}\left(r-r_{0}=-0.5 \mathrm{~cm}\right)$.

Edge radial profiles of some plasma equilibrium parameters (such as electron density, electron temperature, and plasma potential) were obtained by using the rake probe in three configurations: (1) with its pins biased by $1 \mathrm{kHz}$ sweeping sinusoidal voltage, (2) with all pins in floating potential, and (3) with a negative DC biasing to measure the ion saturation current. The mean electron temperature was obtained from the probe characteristic curve through a nonlinear least square fit. ${ }^{30}$ The radial profiles of the plasma potential and the electron density were obtained in the configurations (2) and (3), respectively, with the proper temperature corrections. The electron density was obtained from the ion saturation current $\left(I_{\text {sat }}\right)$ and the electron temperature $\left(T_{e}\right)$ using the following expression: $n_{e}=I_{\text {sat }} \sqrt{m_{i} /\left(A^{2} e^{2} T_{e}\right)}$, where $m_{i}$ is the ion mass and $A$ is the probe area. The plasma potential is $\phi_{p} \approx \phi_{f}+\lambda T_{e}$, in which $\lambda \sim 3$ for a cylindrical probe pin in a hydrogen plasma. ${ }^{31}$

\section{EXPERIMENTAL RESULTS AND DATA ANALYSIS}

\section{A. Global improvement on plasma confinement induced by a biased electrode}

The global confinement improvement observed in the L-H transition induced by a biased electrode is understood as the formation of a transport barrier at the edge of the plasma column. ${ }^{4,10}$ The biasing increases the radial electric field gradient at the edge of the plasma, which enhances the edge $E \times B$ shear layer, without necessarily heating the plasma. Improved plasma confinement was successfully achieved in the TCABR tokamak by using a biasing electrode with a clear L-H transition behavior. $^{23,32,33}$

The present experiment was carried out with a plasma current around $85 \mathrm{kA}$ and a central chord line-averaged electron density of (1.2-1.4) $\times 10^{19} \mathrm{~m}^{-3}$, without external perturbation. The biasing was applied between 60 and $80 \mathrm{~ms}$ of the discharge, right at the plasma current plateau phase. The biasing effect on the line averaged plasma density, $H_{\alpha}$ line, and stored plasma energy $\left(W(t) \propto I_{p}(t)^{2} \beta_{\theta}(t)\right)$ normalized by its time average between 55 and $60 \mathrm{~ms}\left(W_{0}\right)$ can be seen in Fig. 3 for five different configurations: no biasing, $+150 \mathrm{~V},+200 \mathrm{~V},+250 \mathrm{~V}$, and $+300 \mathrm{~V}$.

The plasma confinement improvement is gradual, i.e., the higher the voltage on the electrode, the more intense the change induced by it. At $+300 \mathrm{~V}$, a large increase in the density (a factor of about 1.7) is observed in Fig. 3(b), a large decrease in the $H_{\alpha}$ line in Fig. 3(c), and an improvement in the stored plasma energy in Fig. 3(d). The bias effect is less marked at $+250 \mathrm{~V}$ and $+200 \mathrm{~V}$ and weak at $+150 \mathrm{~V}$, in agreement with previous results obtained for TCABR. ${ }^{23,34}$

The confinement degradation observed at $+300 \mathrm{~V}$ around $67 \mathrm{~ms}$ could be attributed to a radiative collapse, resulting from a strong increase in the plasma radiation followed by a fast decrease in the temperature. In fact, at this time, $n \approx 2 \times 10^{19} \mathrm{~m}^{-3} \approx 0.2 n_{G}$, where $n_{G}$ is the Greenwald density limit, it is the minimum limit for small triangularity machines beyond which the degradation is observed. ${ }^{35}$

\section{B. Edge radial profiles}

The measurement of the radial profiles at the edge was performed with the rake probe with $5 \mathrm{~mm}$ radial resolution (Fig. 2). From the sweeping voltage and the ion saturation current configuration, the electron density $\left(n_{e}\right)$ and the electron temperature $\left(T_{e}\right)$ were obtained. The profiles are the result of the average over a time window of $10 \mathrm{~ms}$ right after and right before the biasing started. The mean radial profiles of $n_{e}$ and $T_{e}$ at different biasing voltages are shown in Fig. 4.

The electron density profile changes as an effect of biasing with the appearance of a higher gradient close to the Last Closed Flux Surface (LCFS-limiter position in this experiment), compatible with the rise of a transport barrier. On the other hand, the electron temperature profiles do not significantly change for any biasing voltage, supporting the argument that the effective heating power of the electrode biasing is negligible, at least in the edge region. Although a small drop occurs in the $H_{\alpha}$ line signal at $+150 \mathrm{~V}$, no appreciable change is noticed neither in $n_{e}$ nor $T_{e}$, suggesting that the transport barrier is not created at this biasing, and therefore, it is below the L-H transition threshold in TCABR.

Through the measurement of the floating potential, the plasma potential was estimated considering $\phi_{p} \approx \phi_{f}+3 T_{e}$. The effective electron temperature profile was supposed approximately steady along the plateau phase, and so, the changes in the plasma potential are mainly due to variations in the floating potential. The mean radial electric field was obtained by $E_{r}=-d \phi_{p} / d r$. The result for the five scenarios is shown in Fig. 5. 

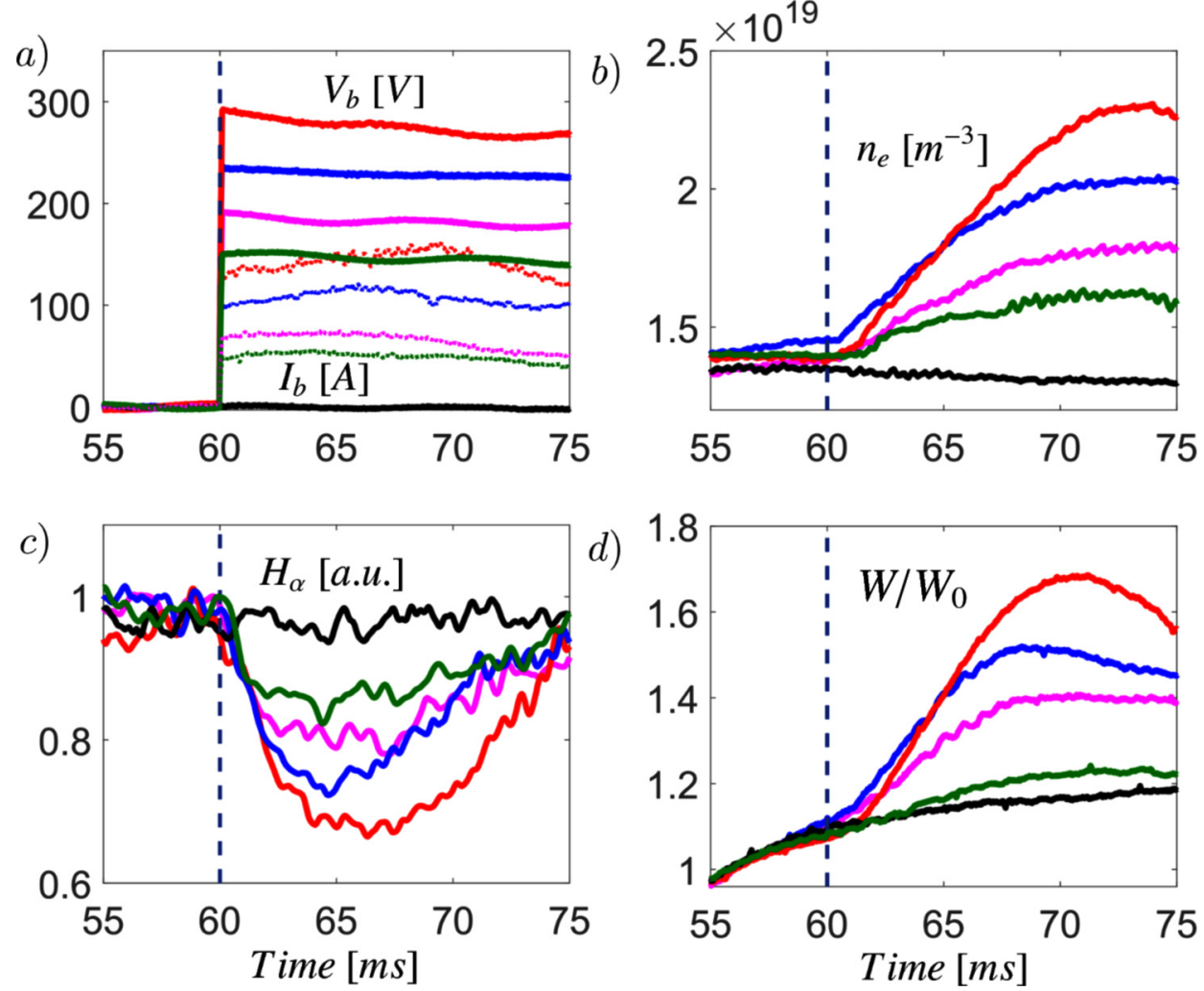

FIG. 3. Global effect of biasing on plasma in TCABR for different conditions, $+300 \mathrm{~V}$ (\#32556), $+250 \mathrm{~V}$ (\#32922), +200 V (\#32920), +150 V (\#34098), and no biasing (\#32554): (a) biasing voltage and current on the electrode, (b) central line density, (c) $\mathrm{H}$ alpha line signal, and (d) stored plasma energy normalized by its time average before biasing $\left(W_{0}\right)$, between 55 and $60 \mathrm{~ms}$.
The figure shows that the higher the biased electrode voltage, the steeper the radial electric field gradient profile near the LCFS. The maximum shear flow $\left(\gamma_{E \times B} \approx-B^{-1} d E_{r} / d r\right)$ occurs in the range between $-0.5 \mathrm{~cm} \leq r-r_{0} \leq 0.5 \mathrm{~cm}$, the shear layer. The maximum shear at $+300 \mathrm{~V}$ biasing is roughly $\gamma_{E \times B}$ $\approx 1.4 \times 10^{6} \mathrm{~s}^{-1}$, while at the same location, the shear before biasing is $\gamma_{E \times B} \approx 0.4 \times 10^{6} \mathrm{~s}^{-1}$. The thickness of the shear layer is weakly dependent on the voltages, and its width is around $1.0 \mathrm{~cm}$. It should be mentioned that the plasma position (the plasma column) changes when biasing is applied, and however, it is smaller than $0.5 \mathrm{~cm}$, which is roughly the uncertainty of the probe position with respect to the limiter position.

Figure 6 shows the mean ion saturation current and the relative fluctuation at two biasing voltages: $+300 \mathrm{~V}$ and $+150 \mathrm{~V}$. The analysis was performed in time slices of $0.5 \mathrm{~ms}$. Since $I_{\text {sat }} \propto n T_{e}^{1 / 2}$ and the mean temperature profiles
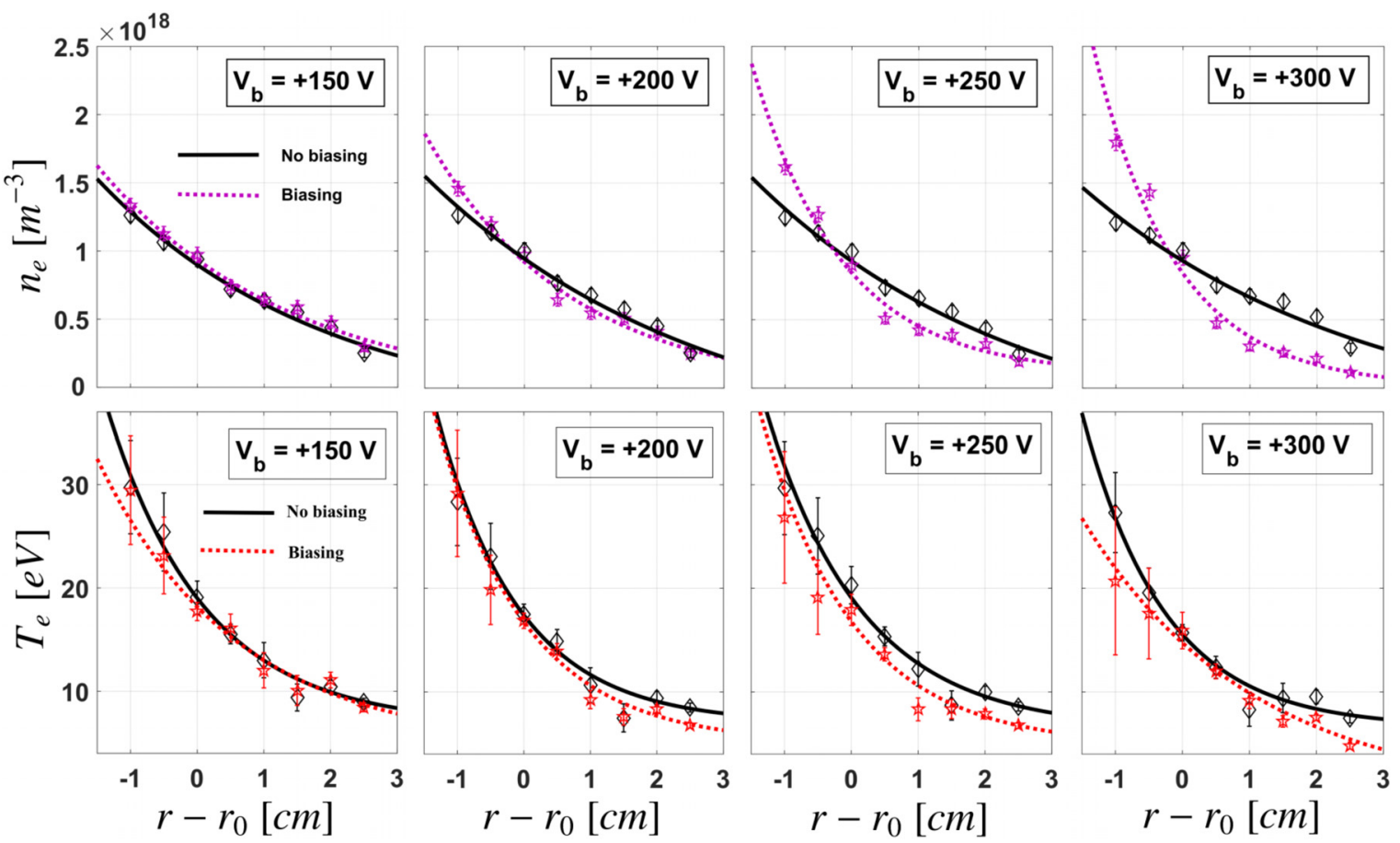

FIG. 4. Electron density (at top) and electron temperature (at bottom) profiles at different biasing voltages. 


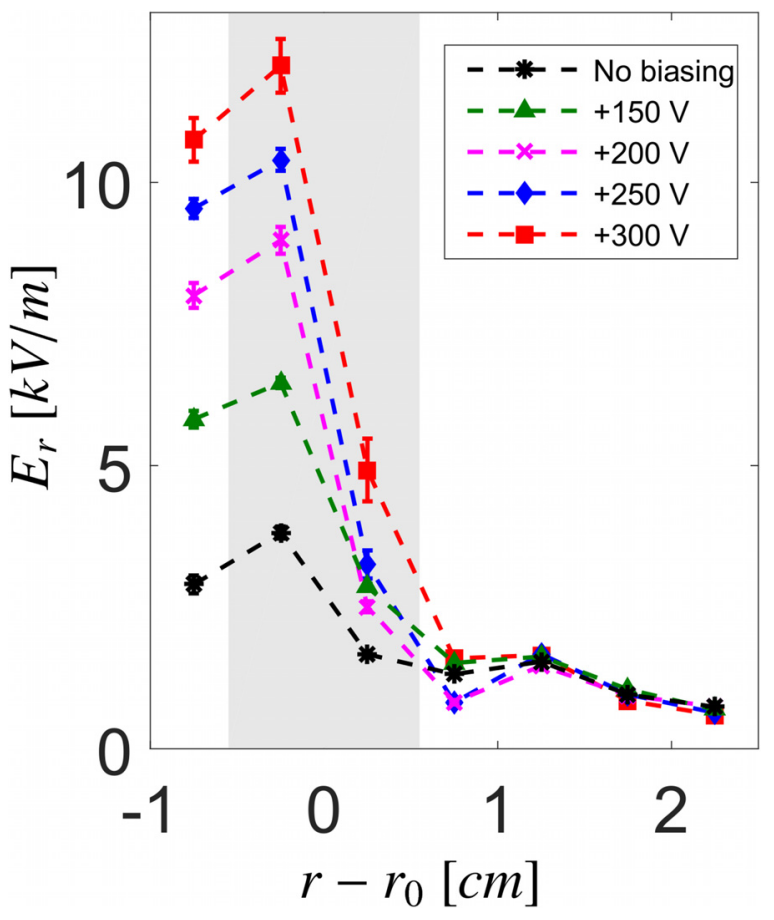

FIG. 5. Radial electric field profiles at +300 V (\#34113), +250 V (\#34128), +200 V (\#34125), +150 V (\#34119), and no biasing (\#34134). The zero in the horizontal axis indicates the limiter position $\left(r_{0}=18.0 \mathrm{~cm}\right)$. The grey area indicates the shear layer region.

are approximately unchanged by the electrode biasing, the behavior depicted in the figure is related directly to the density. Figures 6(a) and 6(c) show that, virtually, there is no change in the average $\left(\bar{I}_{\text {sat }}\right)$ and the relative fluctuation $\left(\delta I_{\text {sat }} / \bar{I}_{\text {sat }}\right)$ of the ion saturation current before and during the $+150 \mathrm{~V}$ biasing. On the other hand, in Fig. 6(b), two clear phases can be noticed at $+300 \mathrm{~V}$ : a flatter bursty profile before and a steeper profile during biasing, with a higher average value in the edge. Figure 6(d) shows that the relative fluctuation drops close to the LCFS, corresponding to the maximum shear range (Fig. 5) during biasing, and almost does not change in the SOL, where the fluctuations are comparable to the background. The occurrence of the maximum density gradient and the maximum turbulence suppression in the shear layer region (Fig. 5) is consistent with the general framework of the Edge Transport Barrier (ETB). ${ }^{3}$

The time evolution during the transition in the shear layer range (Fig. 5) is shown in Fig. 7 at a biasing voltage of $+300 \mathrm{~V}$. The fast change in the floating potential signal Fig. 7 (a) due to the biasing was selected as a reference (vertical dashed line). The fluctuation part of an ion saturation current near the edge captures the local turbulence feature. Finally, the scalogram of $\tilde{I}_{\text {sat }}$ is shown in Fig. 7(c), where the Marr wavelet ("Mexican Hat") was used ${ }^{36}$ to catch the bursty behaviour of the fluctuation. One can see in Figs. 7(b) and 7(c) that after roughly $0.1 \mathrm{~ms}$, the fluctuation is strongly reduced. Since the biasing rise time was set as $10 \mu \mathrm{s}$, we conclude that turbulence suppression in this experiment occurs on a time scale smaller than $\sim 100 \mu \mathrm{s}$, in agreement with L-H transition simulations. ${ }^{27}$

We also notice from Figs. 6(b) and 7 that the turbulence suppression and $\nabla p(p \simeq n T)$ have a distinct evolution time. The latter reaches its stationary profile (supposed to be the maximum gradient profile) $5 \mathrm{~ms}$ after the biasing starts, while the massive turbulence suppression occurs roughly in $\sim 100 \mu$ s. This is a consequence of the plasma inertia. While $E \times B$ shear reconfigures itself only in the shear layer, the $\nabla n$ profile changes propagate through the whole plasma column, requiring a global reconfiguration in order to support the new gradient in the edge. This also suggests that the pressure gradient contribution for the shear flow at the edge has a secondary role in the turbulence suppression at first moment
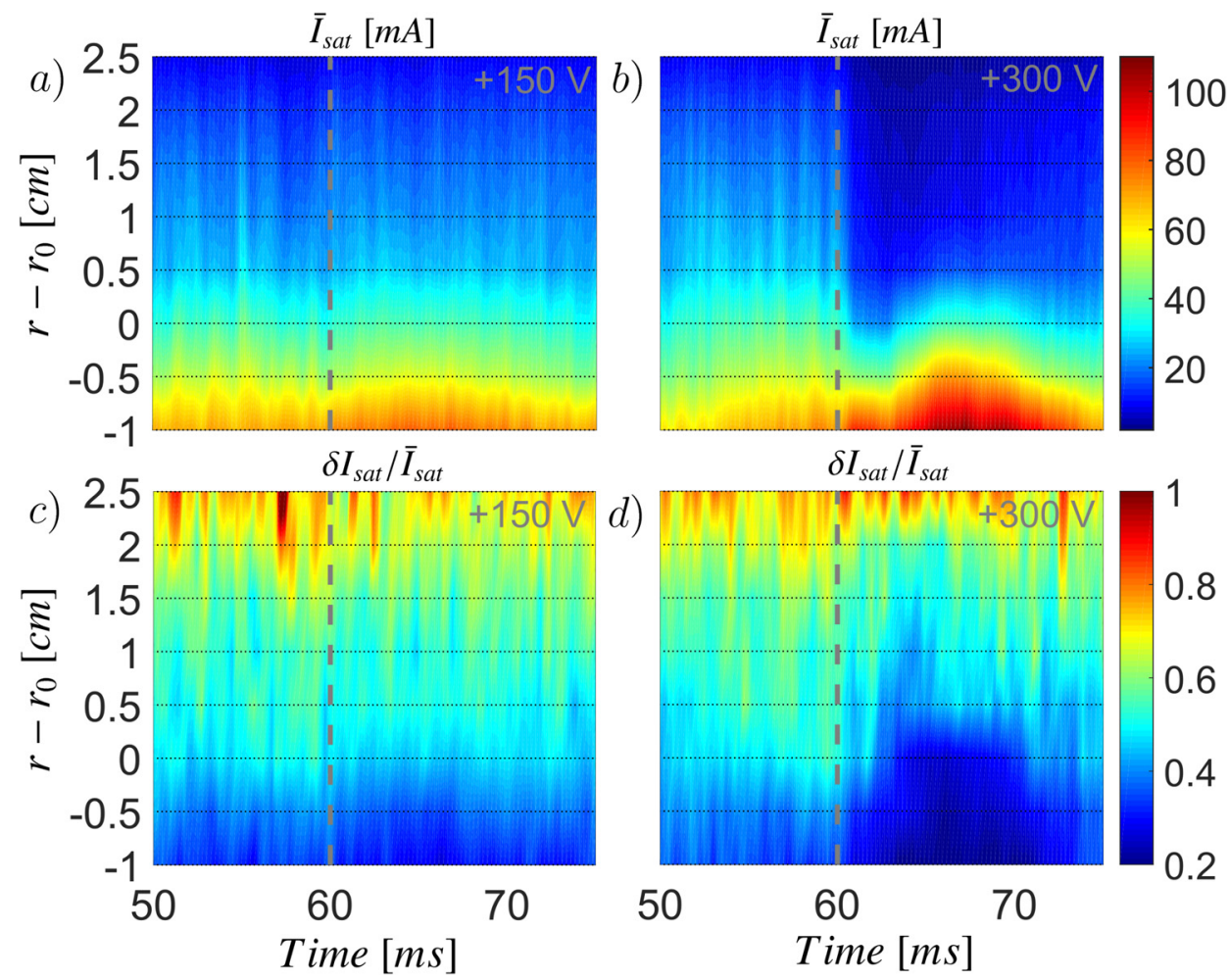

50

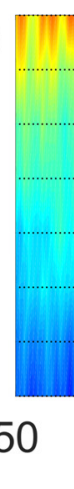

FIG. 6. Time evolution of the mean profile of the ion saturation current at (a) $+150 \mathrm{~V}$ and (b) $+300 \mathrm{~V}$ and its relative fluctuation at (c) $+150 \mathrm{~V}$ and (d) $+300 \mathrm{~V}$. The horizontal lines are the probe pin position with respect to the limiter position. The vertical dashed line indicates the start of biasing. 

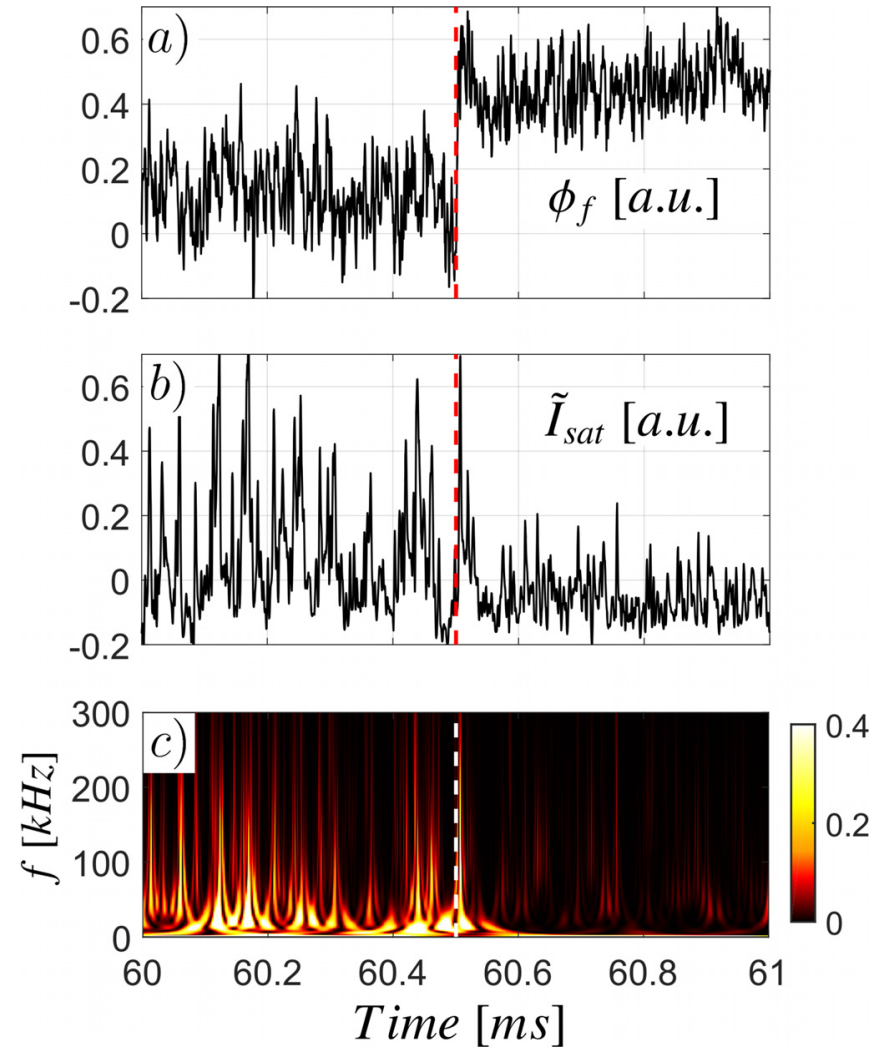

FIG. 7. Time evolution of plasma parameters inside the shear layer (Fig. 5) during the $\mathrm{H}$-mode transition: floating potential in (a), ion saturation current in (b), and Marr wavelet scalogram in (c) are compared in a time window of $1 \mathrm{~ms}\left(t_{0} \pm 0.5 \mathrm{~ms}\right)$ during the transition. The time reference $t_{0}$ was taken as the instant of time of the sudden increase in the fluctuation signal $\phi_{f}$ caused by the electrode biasing (vertical line).

(right after biasing is applied), but it becomes important once the ETB is fully formed [Fig. 6(d)].

The degradation effect is appreciable in Figs. 6(b) and 6(d). The density reaches its maximum around $67 \mathrm{~ms}$, supporting the Greenwald density limit effect for circular plasmas (Sec. III A).

\section{Turbulent particle transport}

The fluctuation of the density $\left(\tilde{n}_{e}\right)$ and the poloidal electric field $\left(\tilde{E}_{\theta}\right)$ can generate a radial particle flux since the radial component of $E \times B$ is $v_{r}^{E \times B}=E_{\theta} / B$,

$$
\Gamma_{r}=\frac{1}{B}\left\langle\tilde{n}_{e} \tilde{E}_{\theta}\right\rangle,
$$

where $\mathrm{B}$ is the toroidal magnetic field and the brackets mean time-averaged. Alternatively, this expression can be decomposed in frequency by writing it as a function of the crosspower spectrum between the fluctuation of density and potential $\left(S_{n \phi}\right),{ }^{37}$ considering $k_{\theta}=\theta_{12} / d\left(\theta_{12}\right.$ is the phase angle between two poloidal spaced potential signals)

$$
\begin{aligned}
\Gamma_{r} & =\int_{0}^{\infty} T(\omega) d \omega \\
& =\frac{2}{B} \int_{0}^{\infty}\left|S_{n \phi}(\omega)\right| k_{\theta}(\omega) \sin \alpha_{n \phi}(\omega) d \omega,
\end{aligned}
$$

where $\omega=2 \pi f$ and $T(\omega)$ is the spectral contribution for the total turbulent radial flux. From the experimental point of view, one can assume $\Gamma_{r} \approx\left\langle\tilde{n}_{e} \tilde{v}_{r}\right\rangle \propto\left\langle\tilde{I}_{s} \tilde{E}_{\theta}\right\rangle / B$ since the electron density is proportional to the ion saturation current $\left(n_{e} \propto I_{s}\right)$ and the electric field to the floating potential variation $E \approx\left(\Delta \phi_{f}^{(12)}\right) / d_{21}$.

In Fig. 8, $T(f)$ is shown as a function of time and $\Gamma_{r}(t)$ at two biasing voltages: $+300 \mathrm{~V}$ and $+150 \mathrm{~V}$, located at $17.5 \mathrm{~cm}\left(r-r_{0}=-0.5 \mathrm{~cm}\right)$. A remarkable difference between $T(f)$ at $+150 \mathrm{~V}[$ Fig. 8(a)] and $+300 \mathrm{~V}[$ Fig. 8(b)] and consequently $\Gamma_{r}(t)$ [Fig. 8(c)] is noticed. Without bias, the transport fluctuation in both cases is predominantly at low frequencies, pointed outward (blue in the colorbar scheme), and so, the total fluxes are comparable. Once biasing is turned on, a reduction in the fluctuation mainly at low frequencies is observed at both voltages, but it is extended to higher frequencies at $+300 \mathrm{~V}$, which deeply impacts the total radial flux, as can be seen in Fig. 8(c).

\section{RADIAL WAVENUMBER SPECTRAL SHIFT}

In the traditional decorrelation paradigm, the shift on the radial wavenumber spectrum is expected as a consequence of the turbulence suppression. ${ }^{24,38}$ The spectral shift model, however, states that the turbulence suppression is due to the radial wavenumber spectral shift, which, in turn, is caused by radial parity breaking (reflection symmetric about the flux surface) by the $E \times B$ Doppler velocity shift. ${ }^{6,9}$ This mechanism was first demonstrated in quasilinear turbulent plasma simulations, ${ }^{6,9}$ where the shear of the mean $E \times B$ velocity Doppler shift, followed by a shift of the mean radial wavenumber, was indeed able to suppress the turbulence levels. The behavior found in those simulations was modeled through a new simplified analytic model using a non-linear Bernoulli differential equation ${ }^{9}$

$$
\frac{\partial \Phi}{\partial t}=\gamma_{k_{y}} \Phi+\gamma_{E \times B} k_{y} \frac{\partial \Phi}{\partial k_{x}}-\left(c_{y} k_{y}^{2}+c_{x} k_{x}^{2}\right) \Phi^{2}=0,
$$
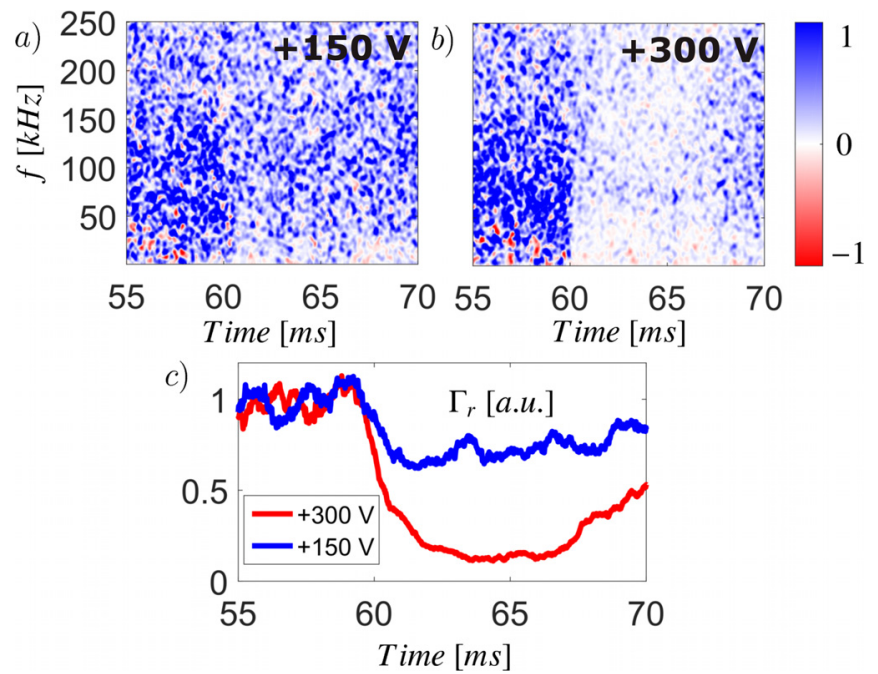

FIG. 8. Spectral contribution for the turbulent particle transport at (a) +150 $\mathrm{V}$ and (b) $+300 \mathrm{~V}$ biasing and (c) total turbulent particle flux at the position: $r-r_{0}=-0.5 \mathrm{~cm}$. In the colorbar scheme, "blue" means outward transport and "red" inward. 
where $k_{x}=k_{r} \rho_{s}$ and $k_{y}=k_{\theta} \rho_{s}\left(\rho_{s}=c_{s} / \Omega_{c}, c_{s}\right.$ is the sound speed and $\Omega_{c}$ is the gyrofrequency), in which $k_{r}$ and $k_{\theta}$ are the radial and poloidal wavenumbers, respectively, $\gamma_{k y}$ is the effective linear growth rate, $\gamma_{E \times B}$ is the $E \times B$ Doppler shear, and $c_{y}$ and $c_{x}$ are constants.

For the non-shear case, the solution of Eq. (3) is the Lorentzian function: $\Phi^{*}=\gamma_{k_{y}} /\left(c_{y} k_{y}^{2}+c_{x} k_{x}^{2}\right)$, where $\gamma_{k_{y}}$ $=c_{y} k_{y}^{2} \Phi$, and in the fully turbulent regime, the mean radial wavenumber, $\left\langle k_{x}\right\rangle=\int_{-\infty}^{\infty} d k_{x} k_{x} \Phi^{2} / \int_{-\infty}^{\infty} d k_{x} \Phi^{2}$, is zero, i.e., the fluctuations in both directions cancel each other. The general solution for non-zero shear (details in Ref. 6) constrained to $\Phi^{*}$ by the limit $\gamma_{E \times B} \rightarrow 0$ is

$$
\Phi=\gamma_{k_{y}} /\left(c_{y} k_{y}^{2}+c_{x}\left\langle k_{x}\right\rangle^{2}+c_{x}\left(k_{x}-\left\langle k_{x}\right\rangle\right)^{2}\right) .
$$

The suppression mechanism, depicted by the spectral shift model in Eq. (3), is taken in two steps: the Doppler shear (r.h.s second term) scatters the turbulent energy from low absolute radial wavenumbers to higher wavenumbers, where the dissipation is stronger (r.h.s third term), leading, therefore, to the reduction of the turbulence spectrum. ${ }^{6,9,26}$ Such a turbulence suppression mechanism was first tested experimentally in EAST tokamak. ${ }^{26}$ It was shown that during the so-called "spontaneous" L-H transition, induced by NBI heating, the shift is gradual until an abrupt phase transition, where the fluctuation levels are suppressed to the background levels. Such spontaneous transition was explained by coupling the original model equation [see Eq. (4)] with an energy balance equation through a diffusive term, without any further additional trigger, as long as the system is heated by an external source.

Figure 9 shows the behavior in time of the spectral shift at different biasing voltages in TCABR. The spectrum was obtained from two floating potentials close to the radial limiter position spaced radially $5 \mathrm{~mm}$ (smaller than the typical radial turbulence correlation length in the $\mathrm{TCABR}^{33}$ )

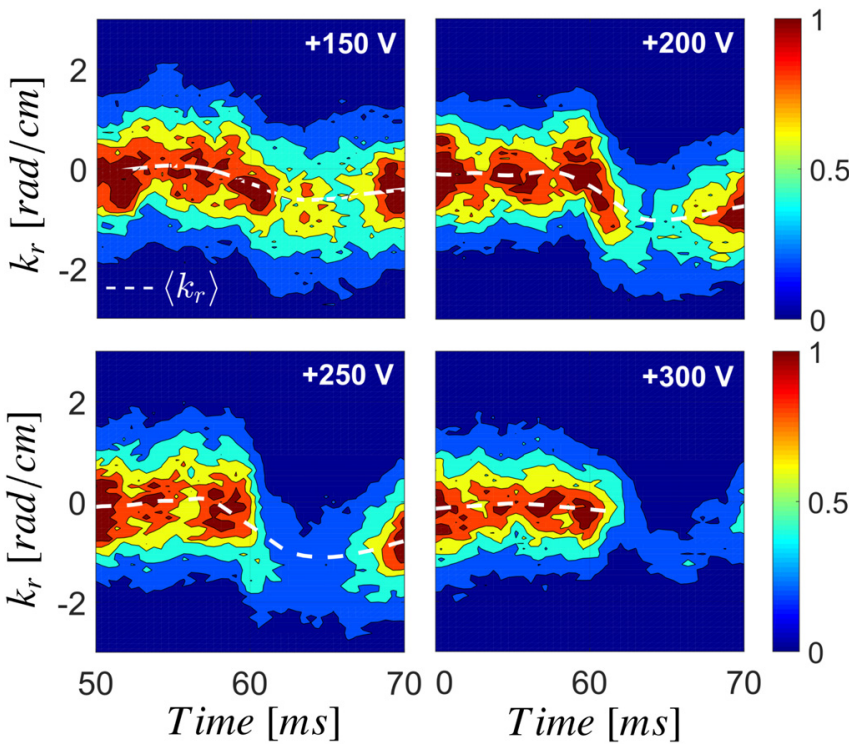

FIG. 9. Wavenumber spectrum at the edge $\left(r-r_{0} \approx 0\right)$ of the TCABR tokamak. The time evolution of the radial wavenumber spectrum is shown at four biases: +150 V (\#34119), +200 V (\#34125), +250 V (\#34128), and $+300 \mathrm{~V}$ (\#34113). The biasing is applied at $60 \mathrm{~ms}$. through the two-point correlation technique. ${ }^{39}$ The condition $-\pi / d_{12}<\alpha_{12} / d_{12}<\pi / d_{12}\left(d_{12}=5 \mathrm{~mm}\right)$ was satisfied to avoid phase ambiguity, and so, the radial wavenumber is within the interval: $\left|k_{r}\right|<k_{r}^{(\max )}$, where $k_{r}^{(\max )} \approx 6.2 \mathrm{rad} / \mathrm{cm}$. The analysis was performed in $1 \mathrm{~ms}$ subwindows, and all data were normalized by the mean spectrum before biasing starts. By the adopted reference, negative $k_{r}$ means outward. The results demonstrated that the confinement improvement due to the electrode biasing behaves as expected by the spectral shift model- the turbulence suppression is stronger when $E \times B$ shear is larger (higher voltages). In particular, at $+300 \mathrm{~V}$, the suppression of the turbulence spectrum exhibits a similar discontinuity in the average radial wavenumber $\left\langle k_{r}\right\rangle$, such as that observed in L-H transition in EAST. ${ }^{26}$ Therefore, the $+300 \mathrm{~V}$ biasing seems to be above the real threshold biasing from which the expected behavior of the $\mathrm{L}-\mathrm{H}$ transition is observed. The lower voltages display the turbulence suppression mechanism due to the spectral shift only, without the L-H transition. This is consistent with the $+330 \mathrm{~V}$ biasing used in Ref. 34 in order to achieve the $\mathrm{H}-$ mode in TCABR tokamak.

Figure 10 shows the turbulent spectrum distribution and the amplitude reduction at $+250 \mathrm{~V}$ voltage biasing in two instants of time. As predicted by both the spectral shift model and gyro-kinetic simulations, ${ }^{6}$ the turbulent spectrum distribution approaches a Lorentzian shape and the shift recenters a new peak in the negative part of $k_{r}$. It was considered, for simplicity, that $\rho_{s}$ is a constant (since the electron temperature does not change with biasing in the edge) and equal to 1 . The instantaneous or short time window analysis of the turbulent fluctuations does not have to be symmetric
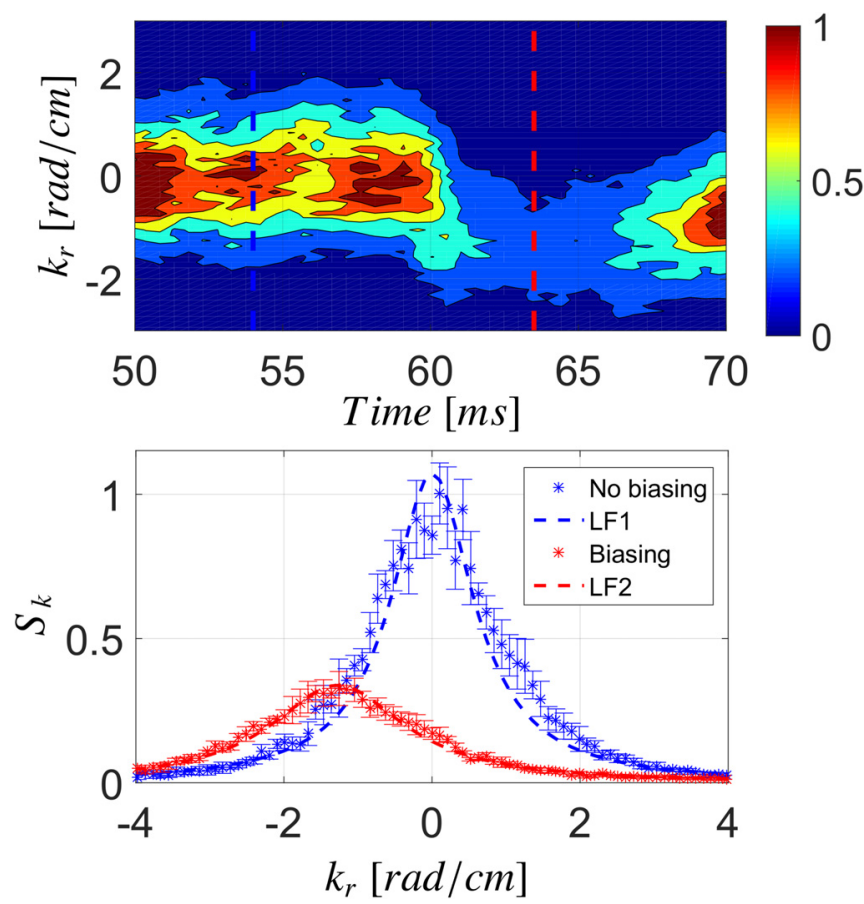

FIG. 10. Wavenumber spectrum distribution before and during $+250 \mathrm{~V}$ biasing (\#34128). When biasing is applied ( $60 \mathrm{~ms})$, the peak of the distribution is reduced, and it is shifted toward the negative side of the $k_{r}$ axis. The dashed curves indicate the least squares fit of the average experimental data over a $3 \mathrm{~ms}$ time window around 54 and $64 \mathrm{~ms}$ considering Eq. (4). 
with respect to $k_{r}$, only the average value within a large time window, which should be related to the time correlation of the turbulence. The shift of the potential spectrum is followed by a large reduction of its amplitude, suggesting that the shift is a necessary condition for the turbulence suppression.

The adapted model to the L-H transition presented in Ref. 26 predicts an asymmetric Lorentzian turbulent spectrum distribution with respect to the peak. This is caused by the diffusion term added in order to couple the model equation [Eq. (3)] with the transport balance equations. Our results for the L-H transition, however, seem to be closer to the standard spectral shift model proposed in Refs. 6 and 9.

From Table I, it is also possible to notice that the fitted $\left\langle k_{r}\right\rangle$ is consistent with the shift observed in the wavenumber spectrum in Fig. 10. The other parameters are also consistent with their own values for high and low $E \times B$ shear environments.

Finally, the radial range affected by the biasing and the behavior of the mean radial wavenumber are shown at $+250 \mathrm{~V}$ in Fig. 11. Before biasing, $\left\langle k_{r}\right\rangle$ and $E_{r}$ are roughly flat throughout the radial interval, with $\left\langle k_{r}\right\rangle$ close to zero. The small $E \times B$ shear does not significantly shift $\left\langle k_{r}\right\rangle$, and so, the high turbulence level (maximum of $S_{k}$ ) makes the spectrum symmetric around zero. When biasing is applied, the radial electric field profile becomes steeper close to the LCFS, enhancing the shear layer within this range. As a consequence, a large shift followed by a spectrum reduction is observed in the same position where the transport barrier develops (Fig. 6). Therefore, the spectral shift model can suitably predict where the transport barrier is created.

\section{DISCUSSION AND CONCLUSIONS}

In this paper, the transition from the regular ohmic heating (L-mode) to the H-mode induced by a biased electrode was addressed. The experimental results obtained in the TCABR tokamak were compared with two different spectral shift models, one related only to the turbulence suppression mechanism $^{6,9}$ and the other adapted to the L-H transition with auxiliary heating. ${ }^{26}$

Both the confinement improvement and the achievement of the H-mode due to the electrode biasing were observed in our experiments. The H-mode is strongly supported at $+300 \mathrm{~V}$ biasing, where the enhancement of the edge pressure gradient in Fig. 6 is consistent with the rise of an Edge Transport Barrier (ETB). This is confirmed by the increase in the central line density and stored plasma energy, as well as the drop of the $H_{\alpha}$ line signal (Fig. 3). Besides, the shear layer in Fig. 5 at $+300 \mathrm{~V}$ biasing allows a large reduction of the radial turbulent particle flux (as depicted in Fig. 8), in

TABLE I. Fitted parameters from Fig. 10. The numbers in parentheses are the errors of the respective quantities. It was considered $k_{r}=k_{x}$ and $k_{\theta}=k_{y}$, that is, $\rho_{s} \sim 1$, for simplicity.

\begin{tabular}{lcccc}
\hline \hline & $\gamma / c_{x}$ & $\left\langle k_{x}\right\rangle$ & $\frac{c_{y}}{c_{x}} k_{y}^{2}+\left\langle k_{x}\right\rangle^{2}$ & $\chi_{\text {red }}^{2}$ \\
\hline$t=54 \mathrm{~ms}$ & $0.490(10)$ & $0.040(20)$ & $0.480(20)$ & $1.20(20)$ \\
$t=64 \mathrm{~ms}$ & $0.400(10)$ & $-1.270(20)$ & $1.19(4)$ & $0.99(20)$ \\
\hline \hline
\end{tabular}

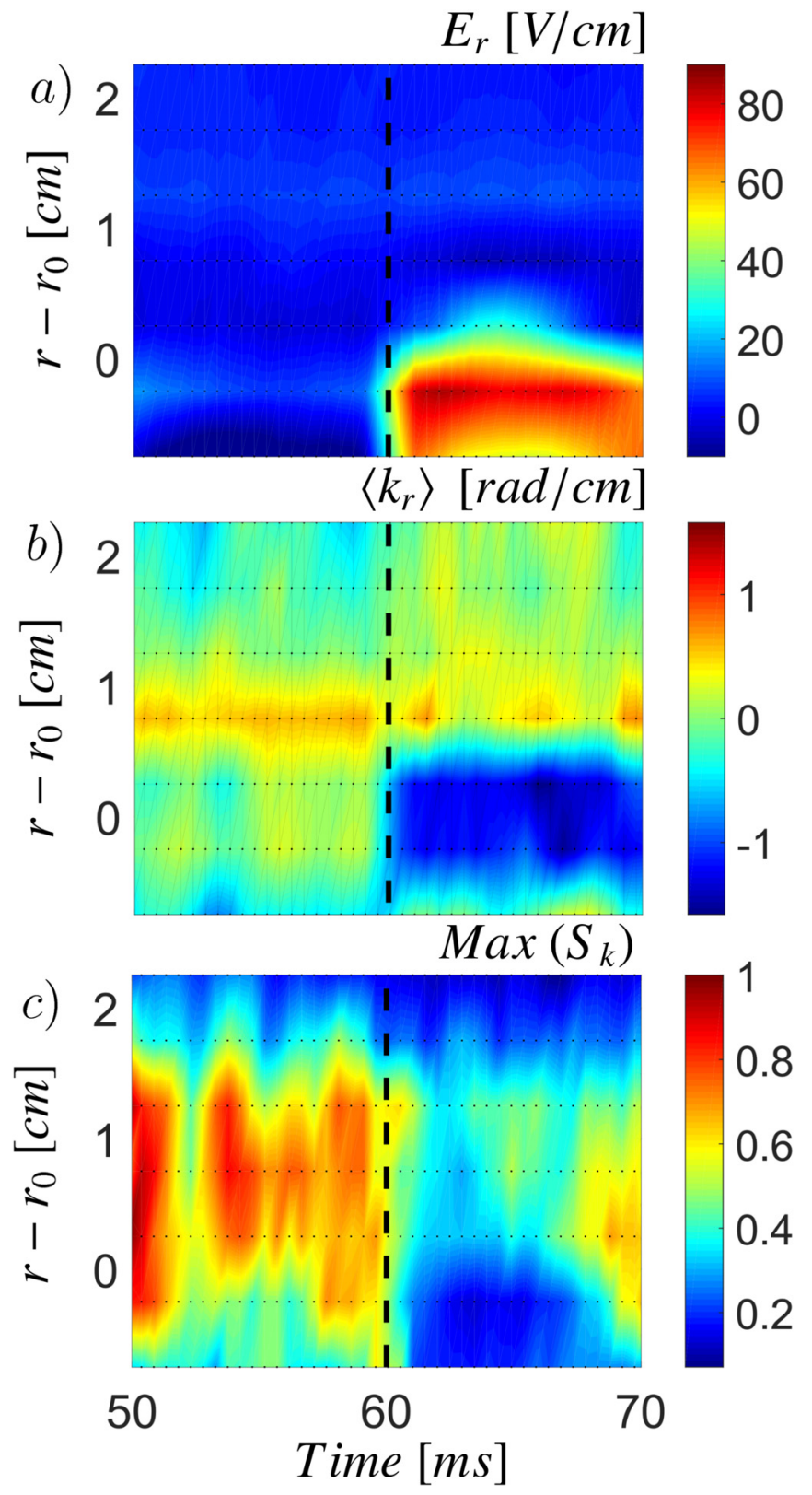

FIG. 11. From the top to the bottom, the following profiles are shown: the radial electric field, the mean radial wavenumber $\left\langle k_{r}\right\rangle$, and the maximum of the spectrum $\operatorname{Max}\left(S_{k}\right)$ as a function of time at $+250 \mathrm{~V}$ biasing (\#34128).

agreement with the $E \times B$ paradigm. ${ }^{3}$ Similar effects also occur at the other biasing voltages, with a clear gradual response with power biasing. At $+150 \mathrm{~V}$, only a small fraction of the low frequency turbulent transport is suppressed, which results in a slight reduction of the net turbulent transport, indicating that this voltage is below the threshold voltage in TCABR, as has been already reported. ${ }^{23,34}$ We also noticed that the $\nabla p$ maximum value occurs a few $m s$ after the $E \times B$ shear settles down in the stationary values as opposed to the fast turbulence suppression $(\sim 100 \mu \mathrm{s})$. This is due to the inertial effects of the plasma that rearrange the whole plasma column in order to support the new steeper gradient.

The behaviour of the turbulence spectrum expected by the spectral shift models was confirmed. For biasing voltages below $+300 \mathrm{~V}$, the shift toward negative $k_{r}$ and the 
consequent turbulence suppression were observed. In particular, at $+250 \mathrm{~V}$, all major aspects of the model, the suppression due to the $\left\langle k_{r}\right\rangle$ shift, and the Lorentzian shape of the spectrum distribution were confirmed, therefore showing that the non-linear damping term in Eq. (3) indeed models the turbulence suppression observed here in the biasing experiment. At $+300 \mathrm{~V}$ biasing, $k_{r}$ shows a similar discontinuity observed in the L-H transition in the tokamak EAST. ${ }^{26}$

The symmetric Lorentzian shape in Fig. 10 shows that the turbulent suppression observed here is well described by the standard spectral shift model ${ }^{6,9}$ rather than the adapted one to the L-H transition. ${ }^{26}$ Hence, the diffusion term, which causes asymmetry in the adapted model, does not seem to play an important role in the turbulence suppression observed in this experiment. In fact, the biasing changes $E_{r}$ and the $E \times B$ shear directly, while in the spontaneous transition by plasma auxiliary heating (as in EAST tokamak), such changes are indirect and ruled by the evolution of the force balance equation, where diffusion processes should be important.

In summary, the general behavior of the turbulence suppression due to the spectral shift $\left\langle k_{r}\right\rangle$ predicted by the spectral shift model was verified in the TCABR tokamak in the electrode biased experiment. The results presented here also point to a secondary role of the diffusion process and inertial effects, such as the rise of the ETB in the L-H transition. Since $E_{r}$ is the controlled parameter in the biasing experiment, the $E \times B$ shear appears to be closely related to the real trigger of the L-H transition. Lastly, despite the consistency between the experimental data and the analytical model, other features of the spectral shift model such as the tilt of the eddies and the toroidal component of the Reynolds stress, which could not be investigated in the present experiment, are necessary in order to assert all predictions of the model. We hope our results could help both in future investigations about the importance of those effects in the L-H transition and in the definitive determination of the trigger mechanism.

\section{ACKNOWLEDGMENTS}

This work was supported by the São Paulo Research Foundation (FAPESP) the University of São Paulo, and the National Council of Scientific and Technological Developments (CNPq), Brazil.

${ }^{1}$ F. Wagner, G. Fussmann, T. Grave, M. Keilhacker, M. Kornherr, K. Lackner, K. McCormick, E. R. Müller, A. Stäbler, G. Becker, K. Bernhardi, U. Ditte, A. Eberhagen, O. Gehre, J. Gernhardt, G. v. Gierke, E. Glock, O. Gruber, G. Haas, M. Hesse, G. Janeschitz, F. Karger, S. Kissel, O. Klüber, G. Lisitano, H. M. Mayer, D. Meisel, V. Mertens, H. Murmann, W. Poschenrieder, H. Rapp, H. Röhr, F. Ryter, F. Schneider, G. Siller, P. Smeulders, F. Söldner, E. Speth, K. H. Steuer, Z. Szymanski, and O. Vollmer, Phys. Rev. Lett. 53, 1453 (1984).

${ }^{2}$ H. Biglari, P. H. Diamond, and P. W. Terry, Phys. Fluids B: Plasma Phys. 2, 1 (1990).

${ }^{3}$ K. H. Burrell, Phys. Plasmas 4, 1499 (1997).

${ }^{4}$ F. Wagner, Plasma Phys. Controlled Fusion 49, B1 (2007).

${ }^{5}$ R. E. Waltz, R. L. Dewar, and X. Garbet, Phys. Plasmas 5, 1784 (1998).

${ }^{6}$ G. M. Staebler, J. Candy, R. E. Waltz, J. E. Kinsey, and W. M. Solomon, Nucl. Fusion 53, 113017 (2013).

${ }^{7}$ G. M. Staebler and R. R. Dominguez, Nucl. Fusion 33, 77 (1993).
${ }^{8}$ R. E. Waltz, G. M. Staebler, J. Candy, and F. L. Hinton, Phys. Plasmas 14, 122507 (2007).

${ }^{9}$ G. M. Staebler, R. E. Waltz, J. Candy, and J. E. Kinsey, Phys. Rev. Lett. 110, 055003 (2013).

${ }^{10}$ J. W. Connor and H. R. Wilson, Plasma Phys. Controlled Fusion 42, R1 (2000).

${ }^{11}$ P. Sauter, T. Pütterich, F. Ryter, E. Viezzer, E. Wolfrum, G. D. Conway, R. Fischer, B. Kurzan, R. M. McDermott, and S. K. Rathgeber, Nucl Fusion 52, 012001 (2012).

${ }^{12}$ P. H. Diamond and Y. B. Kim, Phys. Fluids B 3, 1626 (1991).

${ }^{13}$ E. J. Kim and P. H. Diamond, Phys. Rev. Lett. 90, 185006 (2003).

${ }^{14}$ P. Manz, G. S. Xu, B. N. Wan, H. Q. Wang, H. Y. Guo, I. Cziegler, N. Fedorczak, C. Holland, S. H. Müller, S. C. Thakur, M. Xu, K. Miki, P. H. Diamond, and G. R. Tynan, Phys. Plasmas 19, 072311 (2012).

${ }^{15}$ R. J. Taylor, M. L. Brown, B. D. Fried, H. Grote, J. R. Liberati, G. J. Morales, P. Pribyl, D. Darrow, and M. Ono, Phys. Rev. Lett. 63, 2365 (1989).

${ }^{16}$ I. Ochs and N. Fisch, Phys. Plasmas 24, 092513 (2017).

${ }^{17}$ R. R. Weynants, G. v Oost, G. Bertschinger, J. Boedo, P. Brys, T. Delvigne, K. H. Dippel, F. Durodie, H. Euringer, K. H. Finken, D. S. Gray, J. D. Hey, D. L. Hillis, J. T. Hogan, L. Konen, R. Leners, A. M. Messiaen, A. Pospieszczyck, U. Samm, R. P. Schorn, B. Schweer, G. Telesca, R. v Nieuwenhove, and P. E. Vandenplas, Nucl. Fusion 32, 837 (1992).

${ }^{18}$ L. G. Askinazi, V. E. Golant, S. V. Lebedev, V. A. Rozhanskij, and M. Tendler, Nucl. Fusion 32, 271 (1992).

${ }^{19}$ J. Boedo, D. Gray, S. Jachmich, R. Conn, G. P. Terry, G. Tynan, G. V. Oost, R. R. Weynants, and T. Team, Nucl. Fusion 40, 1397 (2000).

${ }^{20}$ G. V. Oost, J. Adámek, V. Antoni, P. Balan, J. A. Boedo, P. Devynck, I. Duran, L. Eliseev, J. P. Gunn, M. Hron, C. Ionita, S. Jachmich, G. S. Kirnev, E. Martines, A. Melnikov, R. Schrittwieser, C. Silva, J. Stöckel, M. Tendler, C. Varandas, M. V. Schoor, V. Vershkov, and R. R. Weynants, Plasma Phys. Controlled Fusion 45, 621 (2003).

${ }^{21}$ Y. Sun, Z. P. Chen, T. Z. Zhu, Q. Yu, G. Zhuang, J. Y. Nan, X. Ke, H. Liu, and J-TEXT Team, Plasma Phys. Controlled Fusion 56, 015001 (2014).

${ }^{22}$ C. Hidalgo, M. A. Pedrosa, N. Dreval, K. J. McCarthy, L. Eliseev, M. A. Ochando, T. Estrada, I. Pastor, E. Ascasíbar, E. Calderón, A. Cappa, A. A. Chmyga, A. Fernández, B. Gonçalves, J. Herranz, J. A. Jiménez, S. M. Khrebtov, A. D. Komarov, A. S. Kozachok, L. Krupnik, A. LópezFraguas, A. López-Sánchez, A. V. Melnikov, F. Medina, B. van Milligen, C. Silva, F. Tabarés, and D. Tafalla, Plasma Phys. Controlled Fusion 46, 287 (2004)

${ }^{23}$ I. C. Nascimento, Y. K. Kuznetsov, J. H. F. Severo, A. M. M. Fonseca, A. Elfimov, V. Bellintani, M. Machida, M. V. A. P. Heller, R. M. O. Galvão, E. K. Sanada, and J. I. Elizondo, Nucl. Fusion 45, 796 (2005).

${ }^{24}$ I. Shesterikov, Y. Xu, G. R. Tynan, P. H. Diamond, S. Jachmich, P Dumortier, M. Vergote, M. Van Schoor, and G. Van Oost, Phys. Rev. Lett. 111, 055006 (2013).

${ }^{25}$ M. Spolaore, R. Cavazzana, L. Marrelli, L. Carraro, P. Franz, S. Spagnolo, B. Zaniol, M. Zuin, L. Cordaro, S. D. Bello, G. D. Masi, A. Ferro, C Finotti, L. Grando, G. Grenfell, P. Innocente, O. Kudlacek, G. Marchiori, E. Martines, B. Momo, R. Paccagnella, P. Piovesan, C. Piron, M. Puiatti, M. Recchia, P. Scarin, C. Taliercio, N. Vianello, and L. Zanotto, Nucl. Fusion 57, 116039 (2017).

${ }^{26}$ G. S. Xu, B. N. Wan, H. Q. Wang, H. Y. Guo, V. Naulin, J. J. Rasmussen, A. H. Nielsen, X. Q. Wu, N. Yan, L. Chen, L. M. Shao, R. Chen, L. Wang, and W. Zhang, Phys. Rev. Lett. 116, 095002 (2016).

${ }^{27}$ G. M. Staebler and R. J. Groebner, Plasma Phys. Controlled Fusion 57, 014025 (2015)

${ }^{28}$ R. M. O. Galvão, C. H. S. Amador, W. A. H. Baquero, F. Borges, I. L. Caldas, N. A. M. Cuevas, V. N. Duarte, A. G. Elfimov, J. I. Elizondo, A. M. M. Fonseca, T. M. Germano, G. G. Grenfell, Z. O. Guimarães-Filho, J. L. Jeronimo, Y. K. Kuznetsov, M. A. M. Manrique, I. C. Nascimento, C. J. A. Pires, P. G. P. Puglia, A. P. Reis, G. Ronchi, L. F. Ruchko, W. P. de Sá, R. J. F. Sgalla, E. K. Sanada, J. H. F. Severo, V. C. Theodoro, and D. L. Toufen, J. Phys.: Conf. Ser. 591, 12001 (2015).

${ }^{29}$ R. Galvão, Y. K. Kuznetsov, and I. Nascimento, in 4th Brazilian Meeting of Plasma Physics (1996), p. 040.

${ }^{30}$ D. Desideri and G. Serianni, Rev. Sci. Instrum. 69, 2354 (1998).

${ }^{31}$ C. Silva, J. Adamek, H. Fernandes, and H. Figueiredo, Plasma Phys. Controlled Fusion 57, 025003 (2015).

${ }^{32}$ I. C. Nascimento, Y. K. Kuznetsov, Z. O. Guimarães-Filho, I. El ChamaaNeto, O. Usuriaga, A. M. Fonseca, R. M. Galvão, I. L. Caldas, J. H. 
Severo, I. B. Semenov, C. Ribeiro, M. V. Heller, V. Bellintani, J. I. Elizondo, and E. Sanada, Nucl. Fusion 47, 1570 (2007).

${ }^{33}$ Y. K. Kuznetsov, I. C. Nascimento, C. Silva, H. Figueiredo, Z. O. Guimares-Filho, I. L. Caldas, R. M. Galvão, J. H. Severo, D. L. Toufen, L. F. Ruchko, A. G. Elfimov, J. I. Elizondo, W. P. De, S. O. C. Usuriaga, E. Sanada, A. V. Melnikov, M. P. Gryaznevich, M. Peres Alonso, A. P. Reis, M. MacHida, D. J. Trembach, T. M. Germano, R. Narayanan, M. Ghoranneviss, R. Arvin, S. Mohammadi, S. R. Tekieh, F. O. Borges, V. Bellintani, G. P. Canal, P. Duarte, R. M. De Castro, G. Vorobyov, M. Mizintseva, V. E. Moiseenko, F. Do
Nascimento, G. Ronchi, and L. M. Schmutzler, Nucl. Fusion 52, 063004 (2012).

${ }^{34}$ F. A. Marcus, I. L. Caldas, Z. O. Guimarães-Filho, P. J. Morrison, W. Horton, Y. K. Kuznetsov, and I. C. Nascimento, Phys. Plasmas 15, 112304 (2008).

${ }^{35}$ M. Greenwald, Plasma Phys. Controlled Fusion 44, R27 (2002).

${ }^{36}$ M. Farge, Annu. Rev. Fluid Mech. 24, 395 (1992).

${ }^{37}$ E. J. Powers, Nucl. Fusion 14, 749 (1974).

${ }^{38} \mathrm{R}$. Balescu, Aspects of Anomalous Transport in Plasmas (CRC Press, 2005), Chap. 16, pp. 383-384.

${ }^{39}$ J. M. Beall, Y. C. Kim, and E. J. Powers, J. Appl. Phys. 53, 3933 (1982). 